\title{
Distribution of GAGA protein on Drosophila genes in vivo
}

\author{
Thomas O'Brien, ${ }^{1,3}$ R. Chris Wilkins, ${ }^{2}$ Charles Giardina, ${ }^{1}$ and John T. Lis ${ }^{1,4}$ \\ ${ }^{1}$ Section of Biochemistry, Molecular and Cell Biology, and ${ }^{2}$ Section of Genetics and Development, Cornell University, \\ Ithaca, New York 14853 USA
}

GAGA protein binds specific CT.GA-rich DNA sequences in vitro, and many of these sequences are required for transcription in vivo. GAGA protein has been implicated in the transcription of numerous Drosophila genes, including $h s p 70, h s p 26$, actin $5 C$, and $U b x$. Here, we examine the in vivo distribution of GAGA protein on a number of Drosophila genes that do and do not have CT-rich sequences by use of a UV cross-linking technique. Prior to heat shock, GAGA protein is associated with the promoter regions of the uninduced hsp 70 and hsp 26 genes. Upon heat shock induction, GAGA protein is recruited to their transcription units with its distribution coincident with that of RNA polymerase II. The recruitment of GAGA protein to the $h s p 70$ gene after an instantaneous heat shock occurs in a $5^{\prime}$ to $3^{\prime}$ manner with kinetics similar to RNA polymerase. GAGA protein has been shown to disrupt nucleosomes both in vivo and in vitro. We propose that GAGA protein may function in vivo both by binding constitutively to its high-affinity binding sites and by spreading through the induced gene opening the chromatin structure allowing polymerase to elongate efficiently.

[Key Words: GAGA protein; heat shock; transcription; chromatin]

Received October 12, 1994; revised version accepted March 14, 1995.

In vivo transcription requires the presence of numerous proteins in addition to the core basal transcription factors. Many of these proteins act as transcriptional activators, stimulating transcription when bound to a template, whereas others are capable of inhibiting transcription. There exists another set of transcription factors that do not function by activating or repressing transcription per se but, rather, function as antirepressors (Croston et al. 1991). One factor that appears to be in this category is GAGA protein. GAGA protein specifically binds to CT-rich sequences, $(\mathrm{CT} \cdot \mathrm{GA})_{n}$, found in the promoters of many Drosophila genes, such as the heat shock genes $h s p 70$ (Gilmour et al. 1989; Lee et al. 1992) and hsp26 (Glaser et al. 1990; Lu et al. 1992), the actin $5 C$ gene (Chung and Keller 1990), the Ubx gene (Biggin and Tjian 1988), the engrailed gene (Soeller et al. 1988), the E74 gene (Thummel 1989), and the histone genes (Gilmour et al. 1989). In some cases, it has been demonstrated that these sequences are required for optimal transcription in vivo, such as for hsp26 (Glaser et al. 1990; Lu et al. 1992), hsp70 (Lee et al. 1992), actin 5C (Chung and Keller 1990), and the E74 gene (Thummel 1989).

In vivo, GAGA protein can activate transcription from a template containing GAGA-binding sites fused to the

\footnotetext{
${ }^{3}$ Present address: Howard Hughes Medical Institute, Department of Molecular and Cell Biology, University of California, Berkeley, California 94720 USA.

${ }^{4}$ Corresponding author.
}

CAT reporter gene. GAGA protein stimulated transcription from this reporter in a manner dependent on the number of GAGA-binding sites and the level of GAGA protein present in the cell (Soeller et al. 1993), so it was suggested that GAGA protein can act as a potent transcriptional activator. However, in vitro, GAGA protein was not found to activate transcription but was found to have the ability to overcome the negative effects that histone $\mathrm{Hl}$ protein has on transcription (Croston et al. 1991). Therefore, it was proposed that GAGA protein does not act as a classical transcriptional activator but, rather, functions to counteract $\mathrm{Hl}$-mediated repression of transcription. It was recently found that when chromatin is assembled on the $h s p 70$ promoter in vitro, recombinant GAGA protein could disrupt the nucleosomes surrounding the GAGA-binding sites (Tsukiyama et al. 1994). Also, for the hsp26 gene, the CT-rich sequences are required for the formation of the normal DNase I hypersensitive sites (Lu et al. 1992), suggesting that interaction of GAGA protein with these sequences enhances promoter accessibility.

The uninduced heat shock genes hsp 70, hsp26, and hsp27 each contain an RNA polymerase II that has initiated transcription but has paused after synthesizing a short transcript of only 20-50 bases (Rougvie and Lis 1988, 1990; Giardina et al. 1992; Rasmussen and Lis 1993). After heat shock, heat shock factor (HSF) binds upstream of these promoters and activates transcription (Wiederrecht et al. 1987; Wu et al. 1987; Thomas and 
Elgin 1988; Clos et al. 1990), presumably by stimulating elongation of the paused polymerase $/ \mathrm{O}^{\prime} \mathrm{Brien}$ and Lis 1991; Giardina et al. 1992). Therefore, in uninduced cells, RNA polymerase has access to a heat shock promoter and can initiate transcription in the absence of activator. The CT-rich sequences upstream of the $h s p 70$ and $h s p 26$ genes are essential for heat shock induction, as modification of these sequences dramatically reduces the heat shock response (Glaser et al. 1990; Lee et al. 1992; Lu et al. 1992, 1993). Also, point mutations within the GAGA-binding sequences decrease the level of paused polymerase, suggesting that GAGA binding may be required for polymerase to enter the promoter (Lee et al. 1992). Considering the recent demonstration of the ability of GAGA protein to disrupt nucleosomes surrounding the $h s p 70$ promoter in vitro (Tsukiyama et al. 1994) and its ability to act as an antirepressor (Croston et al. 1991), it would appear that GAGA protein may function by binding to the CT-rich sequences upstream of these promoters and opening the chromatin structure, allowing polymerase to enter and initiate transcription. In the absence of HSF, however, polymerase does not penetrate far into the body of the gene.

Here, we examine the in vivo distribution of GAGA protein on DNA by a UV cross-linking technique. We find that GAGA protein is associated with the promoter regions of the uninduced heat shock genes, but after heat shock, GAGA protein distributes throughout the transcription units. The kinetics of GAGA protein recruitment to the induced $h s p 70$ gene suggests that it propagates through the gene in a manner similar to RNA polymerase. The distribution on other constitutively expressed genes is also examined.

\section{Results}

Generation of GAGA protein-specific antibody

Antibody directed against GAGA transcription factor was generated by use of a GST-GAGA fusion protein that contains the carboxy-terminal amino acids 244-519 of the GAGA protein. The amino-terminal 120 amino acids of the GAGA protein is homologous to the transcription factors Broad Complex and tramtrack (Soeller et al. 1993) and is referred to as the POZ domain (Bardwell and Treisman 1994). However, as our antibody was generated against a region of GAGA protein that does not contain this domain, it should not cross-react with these and other related proteins. The antibody was purified by affinity chromatography with a full-length MalGAGA fusion protein (Fig. 1A). The antibody recognizes a defined set of polypeptides in Drosophila Kc nuclear extracts as observed previously in purified GAGA protein preparations (Fig. 1B) (Biggin and Tjian 1988; Soeller et al. 1993). The distribution of GAGA protein on Drosophila polytene chromosomes seen by use of this antibody, and indirect immunofluorescence was similar to that described previously (Tsukiyama et al. 1994; L. Shopland and J.T. Lis, unpubl.). We also purified antibodies directed against two nonoverlapping regions of GAGA protein. One antibody was purified against a portion of GAGA protein encoding a putative zinc finger (residues 244-363, designated GAGA/Zn antibody; Fig. 1A), and the other against a fusion protein containing the glutamine-rich region (amino acids 436-519, designated GAGA/Q antibody; Fig. 1A). Both of these antibodies recognize a similar, but not completely overlapping, series of GAGA polypeptides that are recognized by the GAGA antibody (Fig. 1B, lanes 1,3), and each is highly specific for their corresponding epitopes (Fig. 1C,D). The original GAGA polyclonal antibody, raised to the $\mathrm{Zn}+\mathrm{Q}$ domains, is referred to simply as GAGA antibody throughout the remainder of the text.

\section{Distribution of GAGA protein on the hsp70 gene in vivo}

Although an immunofluorescence analysis provides a global view of the distribution of GAGA protein on Drosophila polytene chromosomes (Tsukiyama et al. 1994), it only provides a low-resolution view of its distribution on specific genes. Here, we used the in vivo UV cross-linking method to yield a higher resolution view of the distribution of GAGA protein on several genes (Gilmour et al. 1991; Walter et al. 1994). In this method, living cells or embryos (in this case Drosophila Kc cell cultures) are irradiated with UV light to covalently crosslink protein to DNA. These protein-DNA complexes are then purificd, restriction digested, and immunoprecipitated with an antibody against a protein that is believed to interact with DNA. The fragments that are immunoprecipitated by the antibody are then visualized by Southern blot hybridization. This technique has been used successfully to examine the distribution of RNA polymerase II (Gilmour and Lis 1985, 1986, 1987; O'Brien and Lis 1993; O'Brien et. al. 1994), the RNA splicing factor B52 (Champlin et al. 1991), topoisomerase I (Gilmour et al. 1986), and the even-skipped, fushi tarazu, and zeste transcription factors (Walter et al. 1994) on various Drosophila genes.

We examined the distribution of GAGA protein on the uninduced $h s p 70$ gene by this in vivo UV cross-linking technique. In Kc cells, there are four copies of $h s p 70$ at chromosome location $87 \mathrm{C}$ and two at $87 \mathrm{~A}$, and these differ slightly in their restriction maps (Mirault et al. 1979). The $5^{\prime} h s p 70$ fragment at $87 \mathrm{C}(-194$ to +1252$)$ containing the CT-rich sequences is immunoprecipitated with GAGA-specific antibody, but not when antibody is omitted (Fig. 2A, lane 5). Therefore, GAGA protein is bound constitutively to the promoter region of the uninduced $h s p 70$ gene, as suggested previously by DNase I footprinting (Gilmour et al. 1989). However, the $5^{\prime}$ fragment from the 87A locus, which does not contain these CT-rich sequences $(-14$ to +1252$)$, is also immunoprecipitated, though at a lower level, indicating that GAGA protein is also bound constitutively to a $5^{\prime}$ fragment that does not contain high-affinity binding sites. Unlike these $5^{\prime}$ fragments, immunoprecipitation of the $3^{\prime}$ fragment is undetectable in uninduced cells.

We also examined the changes in the distribution of 
O'Brien et al.

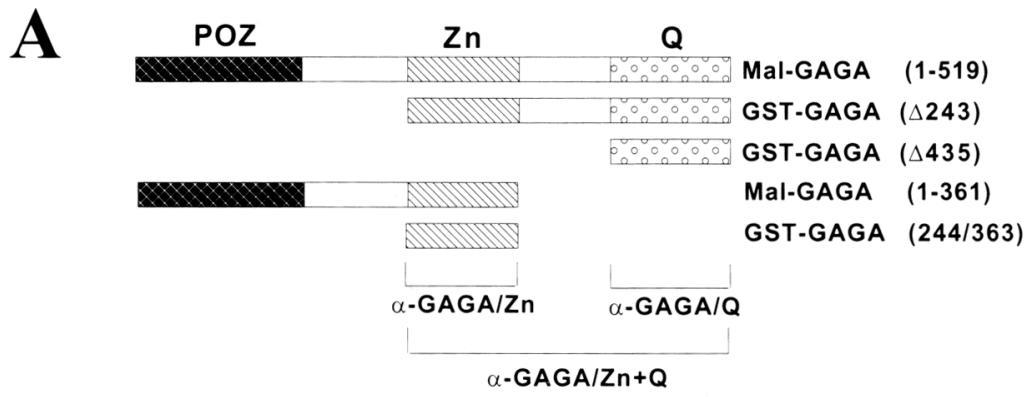

Figure 1. Western analysis of GAGA proteinspecific antibodies. $(A)$ Schematic representation of the GAGA protein and the different fusion proteins generated for affinity purifying specific antibodies. The protein regions corresponding to the $\mathrm{POZ}$, putative zinc finger, and the glutamine-rich domain are labeled. The Mal and GST fusions are indicated but not drawn. The GAGA domains used for affinity purification of specific antibodies are indicated by brackets. (B) Affinity-purified GAGA protein antibodies specifically recognize approximately six main bands in Drosophila $\mathrm{Kc}$ nuclei, in a pattern like that of purified GAGA protein (Biggin and Tjian 1988; Soeller et al. 1993). The GAGA/Zn+Q antibody recognizes six main bands (lane 2), whereas each of the other antibodies recognizes different combinations of these polypeptides (lanes 1,3). (C) The GAGA/Zn antibody specifically recognizes only fusion proteins that contain the GAGA zinc finger region. (D) The GAGA/Q antibody specifically recog. nizes only fusion proteins that contain the GAGA glutamine-rich region.

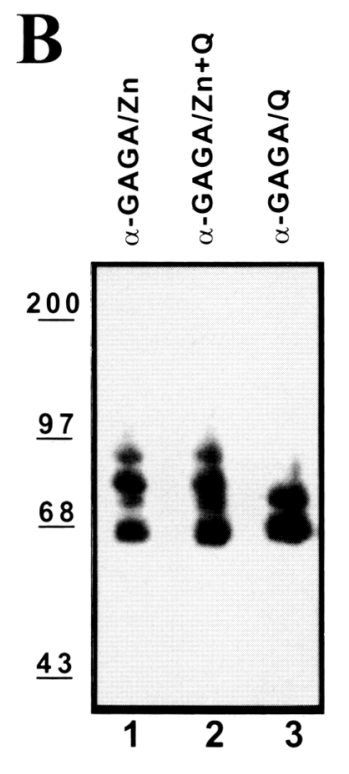

C
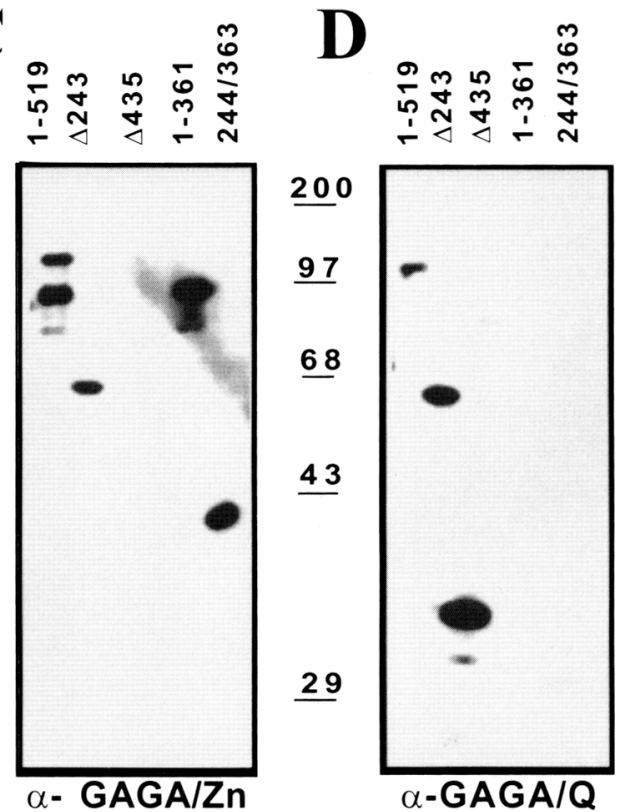

GAGA factor on the $h s p 70$ gene on heat shock. After induction, cross-linking to the $87 \mathrm{C} 5^{\prime}$ fragment increases approximately twofold and the 87A 5 ' fragment approximately three- to fourfold (Fig. 2A, lane 6). Surprisingly, now GAGA protein also cross-links to the $3^{\prime}$ half of the gene with levels at least 10 -fold higher than that seen in uninduced cells.

We also examined the distribution of GAGA protein on the $h s p 70$ gene after treating cells with DRB. DRB is a potent inhibitor of transcription, as treatment of cells with DRB prior to heat shock prevents elongation of RNA polymerase II farther than $\sim 800 \mathrm{bp}$ into the induced hsp70 gene (Giardina and Lis 1993). By use of the UV cross-linking assay with an antibody against RNA polymerase II, we find that DRB treatment of cells prior to heat shock causes RNA polymerase to be restricted predominantly to the $5^{\prime}$ half of the hsp 70 gene (Fig. 2A, lane 12). Likewise, GAGA protein is restricted to this same region and is undetectable on the $3^{\prime}$ fragment (Fig. 2A, lane 11). Also, the density of GAGA protein on the $5^{\prime}$ 87A fragment is approximately twofold lower than that found after a normal heat shock, consistent with the idea that in DRB-treated cells, GAGA protein does not spread far into the body of the gene.
The distribution of GAGA protein at the 3 ' ends of the pair of $h s p 70$ genes at the 87A locus was examined in greater detail (Fig. 2B). The bulk of hsp 70 transcription terminates $\sim 250$ bp downstream of the Sall site located at +2161 (Gilmour and Lis 1985, 1986). GAGA protein is present on a $2.1-\mathrm{kb}$ fragment that includes the $3^{\prime}$ end of the hsp 70 gene (Fig. 2B); however, most of the GAGA protein bound to this fragment appears confined to the transcription unit. A $0.8-\mathrm{kb}$ fragment that contains the $3^{\prime}$ end is immunoprecipitated, but fragments farther downstream are not (the $0.5-$ and $3.0-\mathrm{kb}$ fragments; Fig. 2B). As GAGA protein is not associated with fragments adjacent to the SCS site, the proposed boundary of the 87A puff (Kellum and Schedk 1991; Udvardy et al. 1985), it is unlikely to play a role in defining the extent of the induced puff.

To address the specificity of our antibody for GAGA protein, we compared the distribution of GAGA protein on the induced $h s p 70$ gene with antibodies directed against two independent nonoverlapping regions of the GAGA protein (Fig. 1). Both of these antibodies were used to immunoprecipitate cross-linked complexes isolated from heat-shocked cells as done before (Fig. 2A). In each case, the $h s p 705^{\prime}$ and $3^{\prime}$ fragments were immuno- 
A

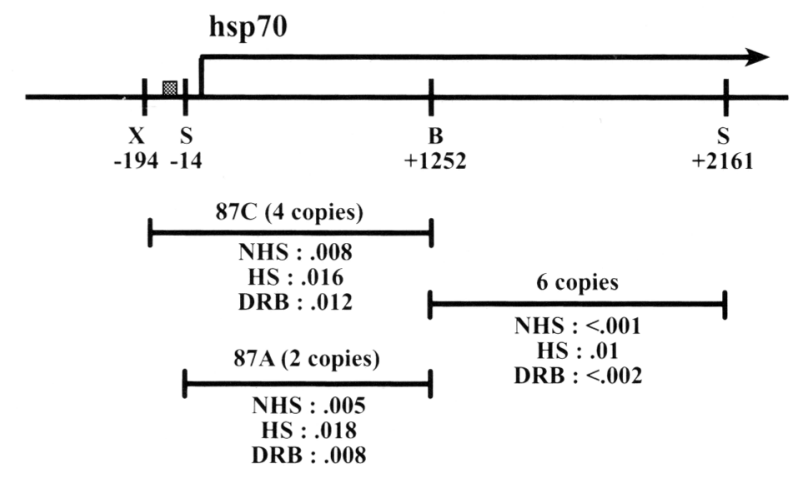

B

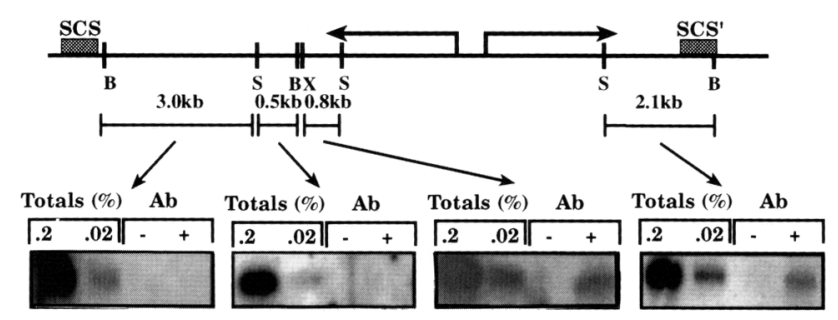

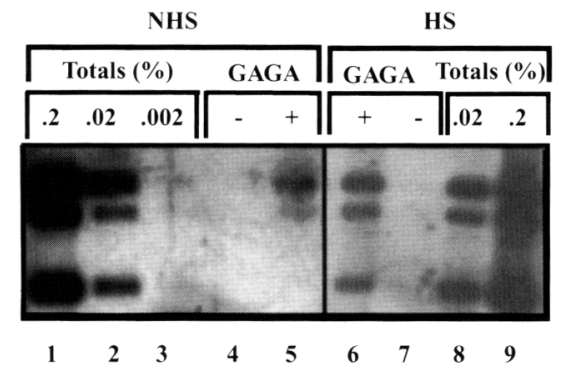
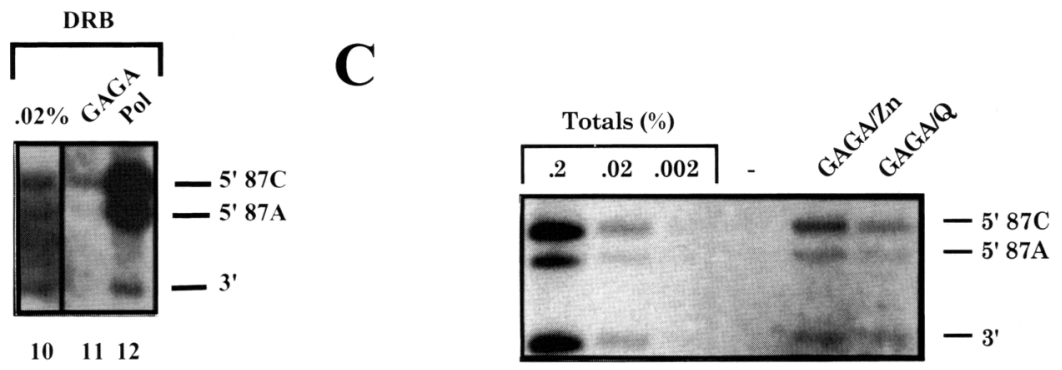

Figure 2. Distribution of GAGA protein on the $h s p 70$ gene in vivo. (A) In vivo UV cross-linking detects GAGA protein on the $h s p 70$ gene. Restriction maps of the hsp70 genes are shown (Mirault et al. 1979), with the restriction sites being BamHI (B), SalI (S), and Xhol (X). The stippled box represents the location of the GAG protein high-affinity binding sites. Protein-DNA complexes were isolated from non-heat-shocked cells (NHS), heat-shocked cells (HS), or cells treated with DRB prior to heat shock (DRB), digested with Xhol/BamHI/SalI, immunoprecipitated with the GAGA-specific antibody, and the resulting DNA examined by Southern blot hybridization. In each case, protein-DNA complexes were immunoprecipitated with $|+|$ or without $|-|$ GAGA antibody, or with an antibody directed against the large subunit of RNA polymerase II (Pol). A percentage of the total amount of DNA that was present in the immunoprecipitation reaction is included (Totals). The numbers below each restriction fragment indicate the percent immunoprecipitation of that fragment (relative to Totals) from uninduced, heat shock-induced cells, or DRB-treated cells. The $h s p 70$ probe was an Xhol fragment that spanned from -195 to +2400 (Rougvie 1989). (B) GAGA protein is restricted to the hsp 70 transcription unit. The distribution of GAGA protein on the $h s p 70$ genes at the $87 \mathrm{~A}$ locus was examined in cells that were heat-shocked for 25 min. The restriction enzyme sites are the same as in $A$. The arrows represent the transcription units of the two hsp 70 genes at this locus. The probes used were as described (Champlin et al. 1991). In each case, protein-DNA complexes were immunoprecipitated with ( + ) or without (-) GAGA-specific antibody. The SCS and the SCS' are the scaffolding sites that are believed to be the boundaries of the heat shock-induced puff (Kellum and Schedk 1991; Udvardy et al. 1985). (C) Antibodies directed against two individual nonoverlapping epitopes of GAGA protein immunoprecipitate both $5^{\prime}$ and $3^{\prime}$ fragments of the induced $h s p 70$ gene. The restriction digestion is the same as in $A$. In each case, protein-DNA complexes were treated with $|+|$ or without $(-\mid)$ affinity-purified antibody directed against the putative zinc finger (GAGA/Zn) or against the glutamine-rich domain (GAGA/Q) of the GAGA protein.

precipitated (Fig. $2 \mathrm{C}$ ). This result provides additional support that the immunoprecipitation of $h s p 70$ DNA is a consequence of interaction with the GAGA protein and not another cross-reactive protein.

\section{GAGA protein recruitment to the induced hsp70 gene occurs with a $5^{\prime} \rightarrow 3^{\prime}$ polarity}

When nucleosomes are assembled in vitro on a template containing the $h s p 70$ promoter, recombinant GAGA protein can disrupt the nucleosomes that surround GAGAbinding sites (Tsukiyama et al. 1994). Consistent with the idea that GAGA may function to decondense chromatin, GAGA was also found to overcome the inhibitory effects of histone H1 (Croston et al. 1991). We were interested in examining whether GAGA protein may play a related role in facilitating elongation by RNA polymerase II by disrupting the chromatin structure of the $h s p 70$ gene. If GAGA protein action is tightly coupled to the progression of RNA polymerase through the gene, then the kinetics of GAGA protein recruitment to the $5^{\prime}$ and $3^{\prime}$ ends of the $h s p 70$ gene after a heat shock should be similar to the kinetics of RNA polymerase elongation.

The distribution of proteins on the $h s p 70$ gene as a consequence of heat-shock induction can be followed at very short time intervals by in vivo UV cross-linking. This was demonstrated initially in a study examining the progression of RNA polymerase II through the $h s p 70$ gene (O'Brien and Lis 1993). Samples of cells removed at 30 -sec intervals after initiation of an instantaneous heat shock can be irradiated with $40-\mu s e c$ bursts of UV light from a Xenon flashlamp. Protein-DNA complexes are 
A

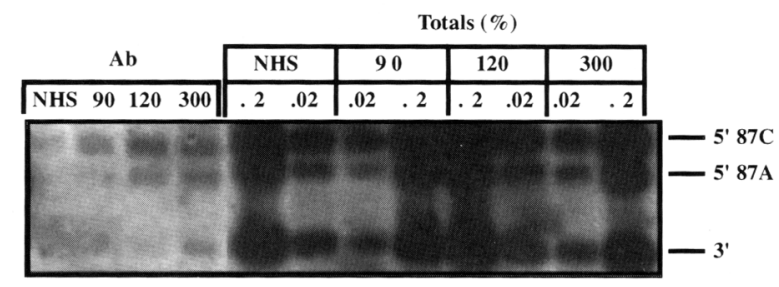

B

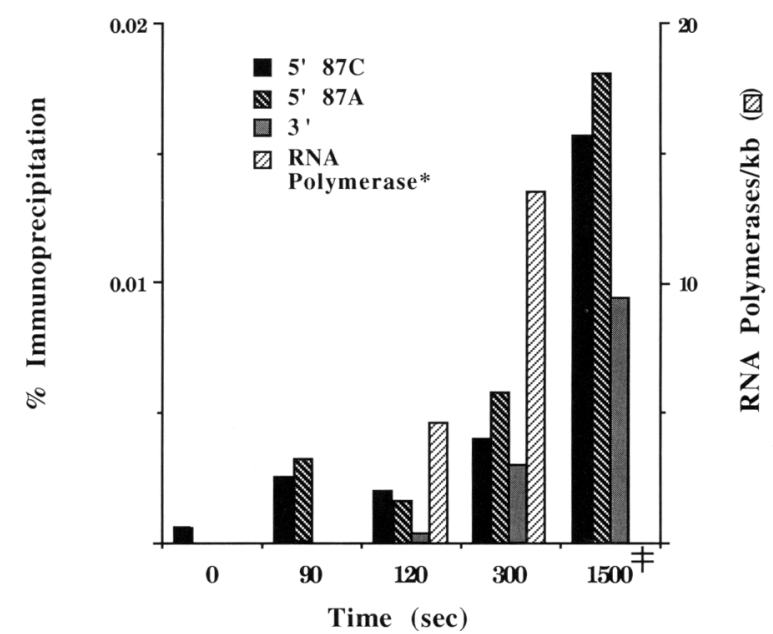

Figure 3. Distribution of GAGA protein on the $h s p 70$ gene at short times after initiation of an instantaneous heat shock. $(A)$ Autoradiographs of filters probed to detect GAGA protein on the $h s p 70$ gene. Cells growing at $23^{\circ} \mathrm{C}$ were given an instantaneous heat shock (see Materials and methods), and samples removed at the indicated time points were irradiated with six flashes from a Xenon flashlamp. For each sample the corresponding 0.2 and $0.02 \%$ totals are shown. The restriction digestion and probe used are the same as used in Fig. 2A. (B) Quantitation of GAGA protein density on the $h s p 70$ gene. The percent immunoprecipitation of each fragment was determined by quantitating the level immunoprecipitated at each time point and comparing it to the totals. The $1500-\mathrm{sec}$ time point ( $25 \mathrm{~min}$ ) is marked (with a double dagger) to indicate that it was taken from data in Fig. 2A (in this case, the sample was irradiated for $10 \mathrm{~min}$ with a long-wave UV lamp so the overall level of immunoprecipitation is higher than for the short time points, which were irradiated with the Xenon flashlamp|. Also shown for comparison is the density of RNA polymerase on the $87 \mathrm{C} 3^{\prime}$ $1.1-\mathrm{kb}$ fragment $(+1285$ to +2400$)$ when immunoprecipitated with antibody directed against RNA polymerase II $\left({ }^{*}\right)$ at similar time points (these data are taken from O'Brien and Lis 1993). The absence of a data point indicates that the level of immunoprecipitation of that fragment was too low to be detected (generally $<0.0003 \%$ ).

then purified, restriction digested, and immunoprecipitated with antibody against RNA polymerase II. This technique demonstrated that the first wave of RNA poly- merase appears on the $3^{\prime}$ end of the hsp 70 gene (a fragment spanning from +1285 to +2400$) \sim 120$ sec after initiation of the heat shock, and by $300 \mathrm{sec}$, the gene is fully induced.

In Figure 3A we examine the distribution of GAGA protein on the $h s p 70$ gene at very short time intervals after initiation of an instantaneous heat shock. In uninduced cells, GAGA protein is found associated predominantly with the $87 \mathrm{C} 5^{\prime}$ fragment, which contains CTrich upstream sequences. Because the overall efficiency of cross-linking by the Xenon flashlamp is lower than for a $10-$ min UV treatment, the sensitivity was insufficient to detect GAGA protein on the 87A $5^{\prime}$ fragment. Within $90 \mathrm{sec}$ after initiation of the heat shock, the level of GAGA protein associated with the $87 \mathrm{~A} 5^{\prime}$ fragment $(-14$ to +1252$)$ is now detectable (Fig. 3A,B), and continues to increase until $300 \mathrm{sec}$. The $3^{\prime}$ fragments, however, are not yet detectable. By $90 \mathrm{sec}$, the first wave of polymerase has elongated from the pause site but has not elongated into the $3^{\prime}$ half of the gene (past +1285 ) (O'Brien and Lis 1993). GAGA protein is detected on the $3^{\prime}$ half of the gene $120 \mathrm{sec}$ after initiation of the heat shock (Fig. 3A,B). By $300 \mathrm{sec}$, when the hsp70 gene is fully induced $\left(\mathrm{O}^{\prime}\right.$ Brien and Lis 1993), the distribution of GAGA protein on the each of the $h s p 70$ fragments is similar to that seen after a 25-min heat shock (Fig. 2B). This would indicate that by $300 \mathrm{sec}$ GAGA protein, like RNA polymerase (O'Brien and Lis 1993), has reached its maximum density on the $h s p 70$ gene. Because the recruitment of GAGA protein to the induced hsp 70 gene has kinetics similar to that found previously for RNA polymerase, GAGA protein and polymerase may track through the hsp 70 gene in a concerted fashion.

\section{GAGA protein binds to lower affinity binding sequences at high concentrations}

The heat shock-induced association of GAGA protein with internal hsp70 sequences could be attributable to the ability of GAGA protein to interact with lower affinity DNA-binding sites during transcription. To assess the feasibility of this idea, DNA binding of GAGA protein to the $h s p 70$ promoter and downstream sequences was assayed by DNase I footprinting. A titration was performed in which the concentration of GAGA protein was increased in threefold increments. At the lowest concentration tested, GAGA protein binding is just detectable to the stronger promoter-binding sites (indicated by solid black bars in Fig. 4A). At the next highest concentration, an almost complete protection is observed at the high-affinity sites. Interestingly, with this intermediate concentration of GAGA protein, partial protection also begins to appear at additional, weaker binding sites (striped bars). The appearance of these weakly protected regions of DNA at a protein concentration required for complete protection of stronger sites can be contrasted with the highly sequence specific DNA-binding protein heat shock factor (HSF). As shown in Figure 4A, HSF completely protects heat shock elements (HSEs) in the hsp70 promoter with no indication of binding at other 


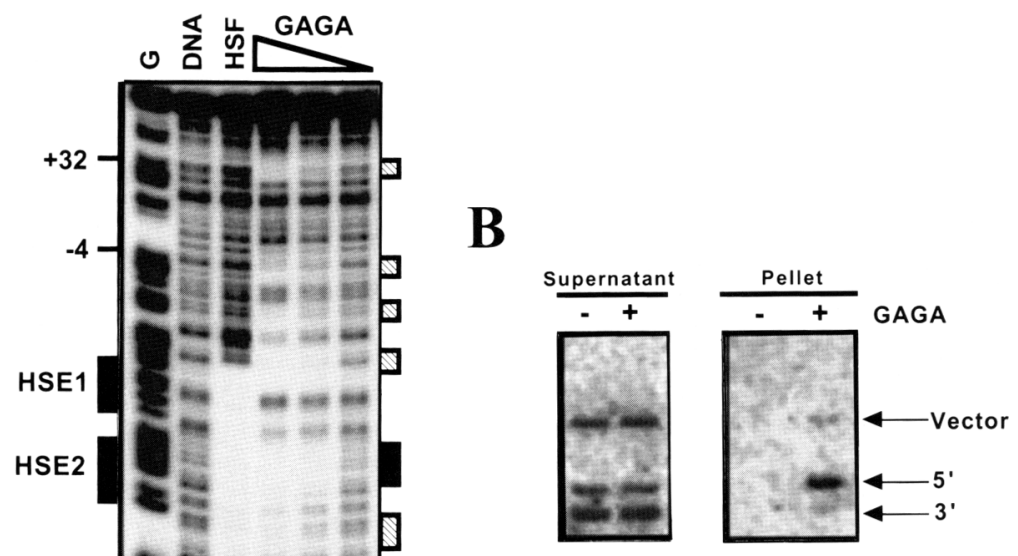

Figure 4. (A) GAGA protein binding to low and high affinity sites on the hsp 70 gene. Lane 2 is the DNase I pattern on purified DNA with no protein $i$ lane 3 shows the DNase I pattern on DNA incubated with purified, recombinant Drosophila Mal-HSF fusion protein; lanes 4-6 are DNase I digestions performed with 3-, 1-, and $0.3-\mu l$ equivalents of purified GSTGAGA fusion protein. Lane 1 is a G-sequence ladder. The high-affinity GAGA protein-binding sites, defined by their ability to be completely protected with $1 \mu$ l of GAGA protein are delineated with solid bars at the side. The weaker binding sites that require $3 \mu l$ of the GAGA protein for complete protection from DNase I are indicated by hatched bars. The number coordinates indicate the position on the gene relative to the transcription start site. The footprinting shown was performed with the GST-GAGA protein; similar results were obtained with the Mal-GAGA protein. (B) GAGA protein-binding in vitro to $5^{\prime}$ and $3^{\prime}$ fragments of $h s p 70$. Radiolabeled fragments of an XhoI- and BamHI-digested p70X2.6 plasmid were incubated with Mal-GAGA protein (1-519). Complexes were immunoprecipitated with GAGA/Zn antibody, and the coprecipitated DNA fragments were subjected to gel electrophoresis and visualized on a Fuji BAS 2000 PhosphorImager. Shown are samples from the supernatant $(5 \%)$ and corresponding pellets $(100 \%),+$ and - GAGA protein.

sites. At the highest concentration of GAGA protein tested, both the weaker and stronger sites are completely protected. DNA binding at the highest concentration of GAGA protein still shows some sequence specificity, because the DNA is not completely covered.

When the sequences at the weak and strong GAGAbinding sites are compared, it is found that the strong sites contain CT or GA repeats 6 bases or longer, whereas the weaker sites correlate with a simpler GAG motif. At the highest concentration of GAGA protein, all GAG sequences in the fragment are occupied. GAGA protein binding to this simple GAG sequence appears to be only severalfold weaker than that of the stronger GAGA-binding sites. It is therefore possible that GAGA protein gains access to these weaker internal GAG sites during transcription (see Discussion).

The 3' half of the hsp70 gene does not appear to have high affinity GAGA sites, yet GAGA protein can associate with this region in vivo. We therefore examined the ability of GAGA protein to bind in vitro to $5^{\prime}$ and $3^{\prime}$ restriction fragments of a cloned $h s p 70$ gene from the $87 \mathrm{C}$ locus (Fig. 4B). These restriction fragments were identical to those used in our in vivo cross-linking experiments (Fig. 2). The radiolabeled fragments were incubated with limiting amounts of GAGA protein and precipitated with GAGA/Zn antibody. The $5^{\prime} h s p 70$ fragment, which contains high affinity sites, shows more binding than the $3^{\prime}$ fragment or the plasmid vector. Therefore, the recruitment of GAGA protein to the $3^{\prime}$ half of the $h s p 70$ gene seen in vivo during heat shock does not appear to be simply a consequence of unmasking high-affinity GAGA-binding sites.

\section{Distribution of GAGA protein on the hsp26 gene}

The hsp26 gene also contains CT-rich sequences, located from -90 to -125 , that are essential for the normal response to heat shock (Glaser et al. 1990; Lu et al. 1992) and that bind GAGA protein in vitro /Gilmour et al. 1989). Here, we examine the distribution of GAGA protein on this gene both before and after heat shock (Fig. 5). A restriction fragment that spans from -600 to +6 is immunoprecipitated prior to heat shock, indicating that, as seen for the $h s p 70$ gene, GAGA protein is constitutively bound to this promoter. A low level of GAGA protein is also associated with the transcription unit /see the EcoRI-Pst fragment that spans from +6 to +2300 ) . A large proportion of this GAGA protein is located near the $5^{\prime}$ end of the transcription unit, as an RsaI-HaeIII 5' fragment is immunoprecipitated with greater efficiency than a $3^{\prime}$ HaeIII-RsaI fragment. Also, the efficiency of immunoprecipitation of this $5^{\prime} \mathrm{RsaI}-\mathrm{Hae}$ III fragment is approximately threefold greater than for an upstream fragment that spans from -600 to +6 . These results would therefore indicate that GAGA protein is constitutively bound to the upstream CT-rich sequences and that it may also be bound to the extreme $5^{\prime}$ end of the transcription unit (like that seen for the uninduced hsp70 gene).

After heat shock, the level of immunoprecipitation of 


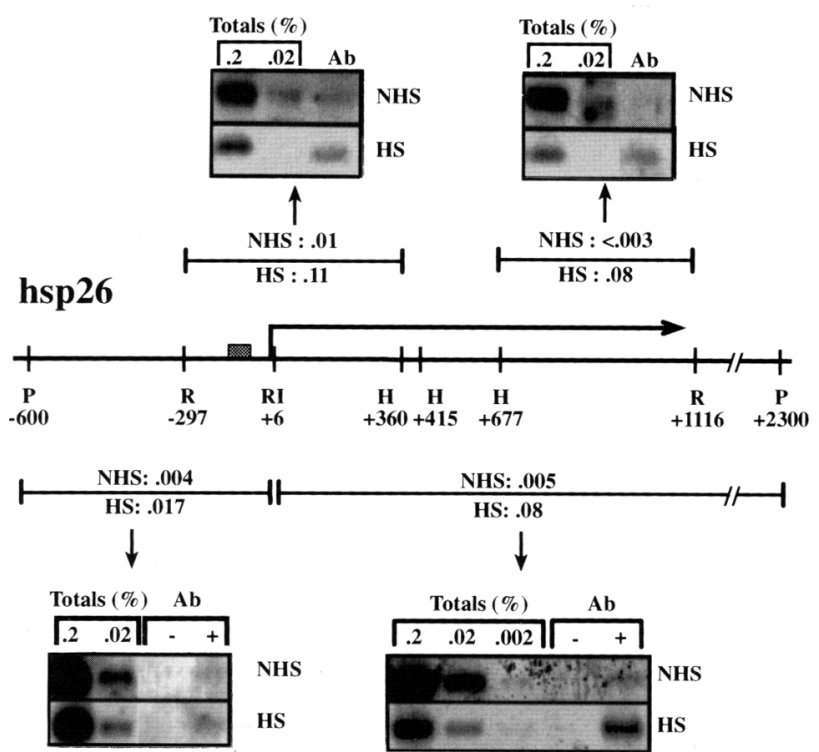

Figure 5. Distribution of GAGA protein on the hsp26 gene. The restriction map of the hsp26 gene is shown, with the enzyme sites being EcoRI (RI), HaeIII (H), RsaI (R), and Pst (P). The location of the CT-rich sequences are shown as a stippled box, and extend from -90 to -125 (Glaser et al. 1990; Lu et al. 1992). (See Fig. 2A legend for details.) The probes used were isolated from the plasmid g26PB (Rougvie 1989).

the promoter fragment (from -600 to +6 ) increases approxiately fourfold (Fig. 5). As seen for the hsp70 genc, GAGA protein is not restricted to the $5^{\prime}$ end of the hsp26 gene but is found distributed on both the $5^{\prime}$ and $3^{\prime}$ halves of the gene. Upon heat shock, immunoprecipitation of the +6 to +2300 fragment and the +677 to +1116 fragment is increased $>16$-fold and 27 -fold, respectively. However, the efficiency of immunoprecipitation of the $5^{\prime}$ RsaI-HaeIII fragment is increased only $\sim 11$-fold over the moderate level of GAGA protein already present on this fragment in uninduced cells.

\section{GAGA protein is also found on the transcription} units of the induced hsp23 and hsp83 genes

The distribution of GAGA protein was also examined on heat shock genes that lack CT-rich repeats in the promoter. The hsp23 gene has not yet been demonstrated to bind GAGA protein, nor does it contain any long CT repeats (the longest found was located at -212 and consisted of CTCTC). After heat shock, DNase I hypersensitive sites have been mapped in the promoter region and are predominantly located downstream of -400 (Cartwright and Elgin 1986). Here, we find that after induction, a fragment that spans this transcription unit is immunoprecipitated by GAGA-specific antibody, indicating the presence of GAGA protein on the hsp23 gene (Fig. 6A) (a fragment spanning from +7 to +2000 is also immunoprecipitated with comparable efficiency; data not shown). In contrast, immunoprecipitation of a fragment that is located $\sim 600 \mathrm{bp}$ upstream of the start is undetectable, indicating that GAGA protein is only associated with the promoter and transcription unit. This also indicates that GAGA protein is not simply being recruited to a region that is open and accessible, as this upstream fragment is between small heat shock genes and is located within the heat shock puff.

Like the $h s p 23$ gene, the $h s p 83$ gene does not contain any long CT repeats; however, it contains DNase I hypersensitive sites upstream of the start site both before and after heat shock (Wu 1980), a paused polymerase (Rougvie 1989), and is constitutively expressed (O'Connor and Lis 1981). We find that GAGA protein is also present in vivo on this constitutively expressed gene (Fig. 6B). Therefore, GAGA does not require long CT repeats to be recruited to an active gene.

\section{Distribution of GAGA protein on non-heat shock Drosophila genes}

The major Drosophila cytoskeletal actin gene actin $5 \mathrm{C}$ contains multiple GAGA elements that are required for transcription (Chung and Keller 1990). This gene contains two main promoters $(\mathrm{P} 1$ and $\mathrm{P} 2)$, with the proximal (P2) promoter being required for constitutive expression in all tissues; however, transcription from both promoters can be detected in Kc cells (Bond and Davidson 1986). Associated with the P2 promoter are five GAGA cle-

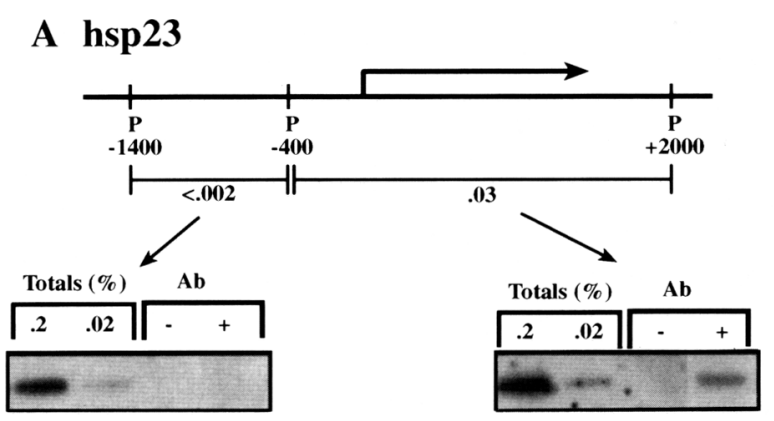

\section{B hsp83}

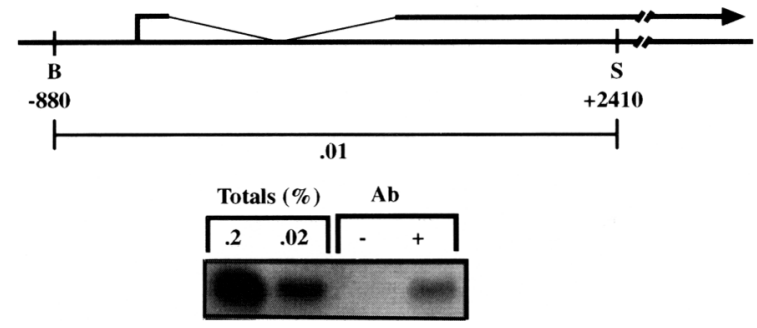

Figure 6. Distribution of GAGA protein on the heat-induced hsp23 and hsp83 genes. (A hsp23) The restriction map of the hsp23 gene is shown, with the enzyme site being PstI (P) / see Fig. 2A legend for details). The probes used were isolated from the plasmid 202.7 (Costlow 1984). (B hsp83) The restriction map of the hsp 83 gene is shown, with the enzyme sites being BamHI (B) and Sall (S) (see Fig. 2A legend for details). The probe used was described previously (O'Brien et al. 1994). 
ments, located between -249 and -86 , and some or all of these are required for optimal expression from this promoter (Chung and Keller 1990). In vivo UV crosslinking demonstrates that GAGA protein is found to be present on this fragment (Fig. 7A). The $3^{\prime}$ fragment is also immunoprecipitated, indicating that, like seen for the induced heat shock genes, GAGA protein is also distributed throughout the body of the actin $5 C$ gene.

It was found previously that GAGA protein bound to the promoter region of the his 3 and his 4 genes of Drosophila in vitro (Gilmour et al. 1989). Therefore, we also examined whether GAGA protein could be detected on the histone repeat. GAGA protein was found to be present on a restriction fragment that contained the transcription units of all the histone genes (Fig. 7B). However, the level of GAGA protein is significantly lower than that found on the induced heat shock genes. This indicates that in addition to DNA sequence, other features of the gene influence binding of GAGA protein.

We also examined whether GAGA protein was associated with the rDNA transcription units of Drosophila.

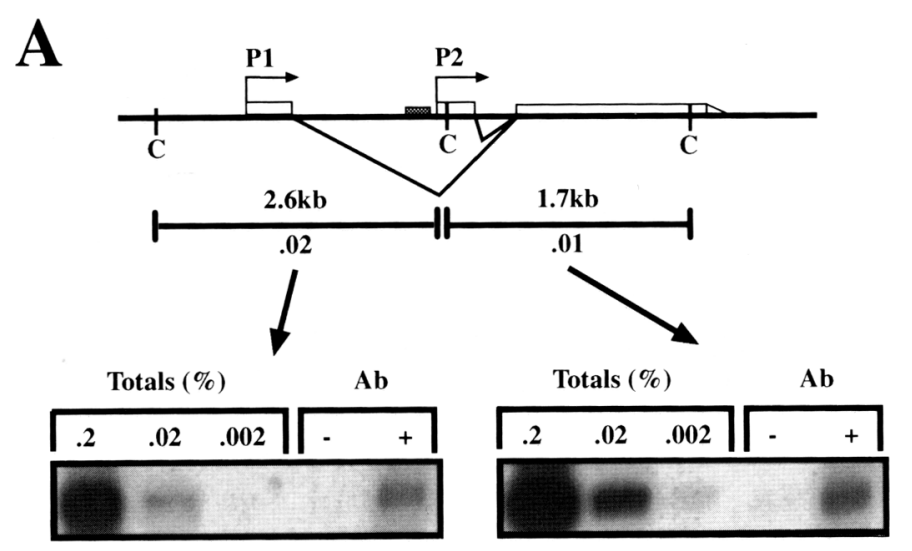

$\mathcal{C}$

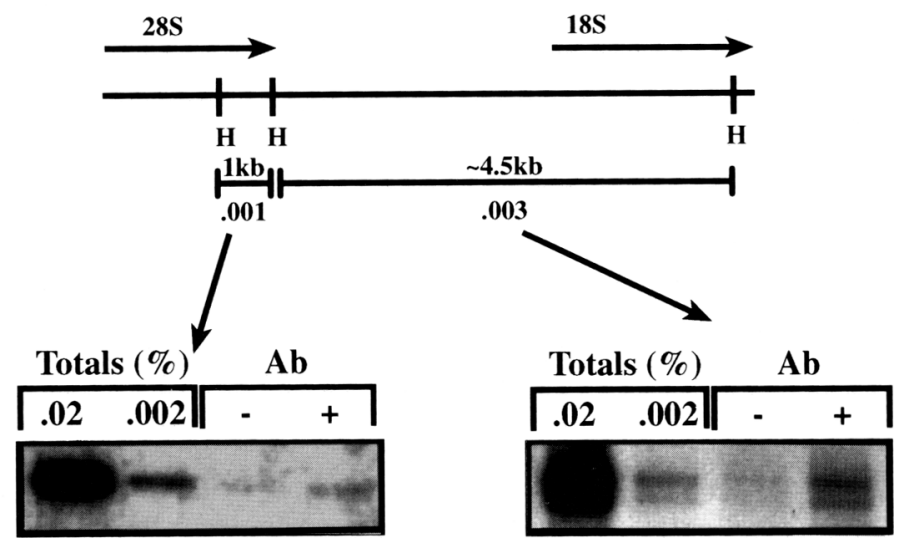

These transcription units are arranged as an $\sim 12-\mathrm{kb}$ unit in Drosophila (Dawid et al. 1978) and are transcribed by RNA polymerase I at very high levels (Miller 1981). We find that GAGA antibody can immunoprecipitate two fragments from this transcription unit that are being actively transcribed (Fig. $7 \mathrm{C}$ ), but the level of immunoprecipitation is similar to that seen for a fragment spanning the his 3 and his 4 promoters. Therefore, GAGA protein is distributed at a very low level throughout a highly active, non-RNA polymerase II-transcribed gene.

\section{Discussion}

GAGA transcription factor has been shown to bind to CT-rich sequences in vitro, and many of these sequences are essential for normal transcription. Here, we demonstrate that, in vivo, GAGA protein is found associated not only with DNA fragments that contain predicted high-affinity binding sites, but also with fragments that contain lower affinity binding sequences. The distribution of GAGA protein, and the kinetics of its recruit-

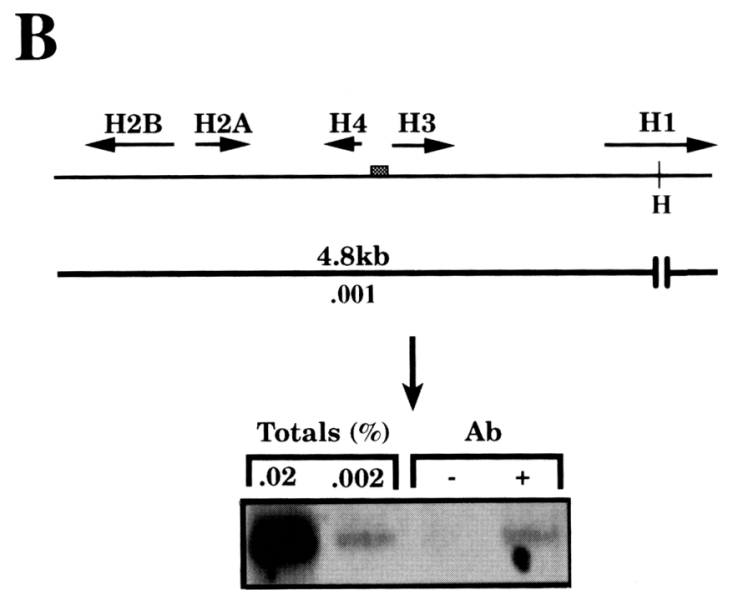

Figure 7. Distribution of GAGA protein on various Drosophila genes. $(A)$ actin $5 C$ gene. The restriction map of the actin $5 C$ gene is shown, with the $C l a \mathrm{I}(\mathrm{C})$ restriction enzyme site. This gene has two main promoters, P1 and P2, both of which are used in Drosophila Kc cells (Bond and Davidson 1986). The CT-rich sequences that bind GAGA protein and are required for constitutive expression from the P2 promoter are shown (Chung and Keller 1990). The probes used were as described (Rougvie 1989). (B) Histone locus. The histone genes are located on a $4.8-\mathrm{kb}$ fragment that is repeated $\sim 100$ times in the Drosophila genome (Lifton et al. 1977). The restriction map of one repeat is shown, with the HindIII $(\mathrm{H})$ restriction enzyme site. The location of the CT-rich sequences that bind purified GAGA protein in vitro are indicated as a stippled box between the $\mathrm{H} 3$ and $\mathrm{H} 4$ promoters /Gilmour et al. 1989|. The probe used was described previously (O'Brien and Lis 1993). (C) rDNA locus. The restriction map of part of the rDNA locus is shown, with the HindIII $(\mathrm{H})$ restriction enzyme sites. A series of fragments migrate in the $\sim 4.5-\mathrm{kb}$ size range, because of the presence of an insertion sequence of different sizes $5^{\prime}$ to the $18 \mathrm{~S}$ transcription unit (Dawid et al. 1978). The number below each fragment is the percent immunoprecipitation. For the $4.5-\mathrm{kb}$ fragment, this number represents the immunoprecipitation of the group of comigrating fragments. The probes used were isolated from the plasmid DmrY22 (Dawid et al. 1978). 
ment to an actively transcribed gene, suggests a role in generating and/or maintaining a transcriptionally active template.

\section{Role of GAGA protein on uninduced heat shock genes}

The promoters of the uninduced heat shock genes are primed for a rapid response to heat shock. Both the $h s p 70$ and $h s p 26$ genes contain an RNA polymerase that has initiated transcription but has paused after synthesizing a short transcript (Giardina et al. 1992; Rasmussen and Lis 1993; Rougvie 1989; Rougvie and Lis 1988). These uninduced promoters also contain at least two other bound proteins, the TATA-binding protein (TBP) (Wu 1984; Thomas and Elgin 1988; Giardina et al. 1992) and GAGA protein. The CT-rich sequences upstream of the hsp70 promoter bind purified GAGA protein in vitro (Gilmour et al. 1989), and these sequences are critical for establishing the paused polymerase at the $5^{\prime}$ end of the hsp70 promoter (Lee et al. 1992). The CT-rich sequences at the $5^{\prime}$ end of the hsp 26 promoter are required for a full heat shock response, as deletion of these in transgenic fly lines dramatically reduces the response to heat shock (Glaser et al. 1990; Lu et al. 1992). Also, indirect immunofluorescence has confirmed that GAGA protein can be detected on both the $87 \mathrm{~A}$ and $87 \mathrm{C}$ loci / the chromosomal location of the $h s p 70$ genes) and on the $67 \mathrm{~B}$ region (the location of the small heat shock genes) in polytene chromosomes from uninduced Drosophila (Tsukiyama et al. 1994).

Here, by in vivo UV cross-linking, we demonstrate that GAGA protein is associated with the promoter regions of both the uninduced $h s p 70$ and $h s p 26$ genes. Surprisingly, we find that GAGA protein is present on fragments that span the 3 ' ends of the $h s p 70$ and $h s p 26$ genes that do not contain predicted high-affinity binding sites for GAGA. In vitro, GAGA protein binds to its highaffinity binding sites but, at high concentrations, also to simpler GAG sequences (Fig. 4). What is the function of GAGA protein on these uninduced promoters? The CTrich sequences upstream of the $h s p 70$ and $h s p 26$ genes are required for the heat shock response and for generating an open promoter (Glaser et al. 1990; Lee et al. 1992; Lu et al. 1992). GAGA protein has also been implicated in establishing the paused polymerase on the hsp 70 gene (Lee et al. 1992). These in vivo studies coupled with our observations suggest a model whereby GAGA protein binds to its high-affinity sites and opens the nucleosome structure of the inactive promoter, allowing polymerase to enter and initiate transcription. GAGA protein may also bind to weaker affinity sites within the $5^{\prime}$ region of the gene, allowing polymerase to begin to elongate into the body of the gene. However, in the absence of heat shock (and HSF) polymerase is unable to elongate efficiently into the body of the gene (see Fig. 8A).

Role of GAGA protein on induced heat shock genes

After heat shock induction, the chromatin structure of the heat shock genes changes dramatically. The transcription units become more sensitive to DNase I digestion (Wu 1980; Cartwright and Elgin 1986), indicating that the coding regions are now more open and accessible. Upon heat shock, we find that GAGA protein is associated with the transcription units of both the hsp 70 and $h s p 26$ genes (Table 1 ; Fig. 8A) and that the association of GAGA protein with the transcription unit is largely coincident with that of RNA polymerase II. By sequence analysis and in vitro binding, we have not detected high-affinity binding sites on the $3^{\prime}$ half of the hsp70 gene. However, we have found that as the concentration of GAGA protein is increased, binding can be detected by in vitro DNase I footprinting to sequences that correlate with the trinucleotide GAG. Binding of GAGA protein to lower affinity sites could account for its wide distribution seen by in vivo UV cross-linking on transcribed genes.

The distribution of GAGA protein on an induced heat shock gene correlates closely with that of RNA polymerase II. GAGA protein is found only on the transcription unit, and when polymerase elongation is inhibited the ability of GAGA protein to associate with the $3^{\prime}$ end of a gene is correspondingly inhibited. A kinetic analysis of GAGA recruitment to the body of the $h s p 70$ gene indicates that it is recruited in a $5^{\prime} \rightarrow 3^{\prime}$ manner, and is found on the $3^{\prime}$ fragment within $120 \mathrm{sec}$ after initiation of an instantaneous heat shock. Previously, we found that the first wave of RNA polymerase elongates through the $h s p 70$ gene with a rate of $\sim 1.2 \mathrm{~kb} / \mathrm{min}$, and is not detected on the $3^{\prime}$ half of the gene until 120 sec after heat shock (O'Brien and Lis 1993). Therefore, it would appear that GAGA protein and polymerase traverse through the hsp70 gene with similar kinetics. Upon heat shock, GAGA protein may propagate through the gene, binding to weaker internal sites, prior or subsequent to polymerase, or as part of the polymerase complex. GAGA protein could function to open the chromatin structure, allowing polymerase to efficiently elongate through the gene (Fig. 8A). As the distribution of GAGA protein on a heat shock gene is similar after either a $5-\mathrm{min}$ or a $25-\mathrm{min}$ heat shock, it would imply that high levels of GAGA protein may also be required to maintain the chromatin in an open configuration.

A high level of GAGA protein was also found on the induced $h s p 23$ and $h s p 83$ genes (Table 1). It was not known whether GAGA protein may bind to sequences within these genes as there are no apparent high-affinity binding sites. However, the recruitment of GAGA protein is specific for the transcription unit as, in the case of $h s p 23$, a region that is immediately upstream of the promoter contains at least 15-fold less GAGA protein. It is possible that lower affinity binding sites may be capable of binding GAGA, a detailed analysis of the GAGA protein consensus binding sequence has not been published. Nevertheless, DNase I hypersensitive sites can be detected at the promoters of these gene both before and after heat shock, implying the presence of DNA bound proteins (Wu 1980; Cartwright and Elgin 1986). 


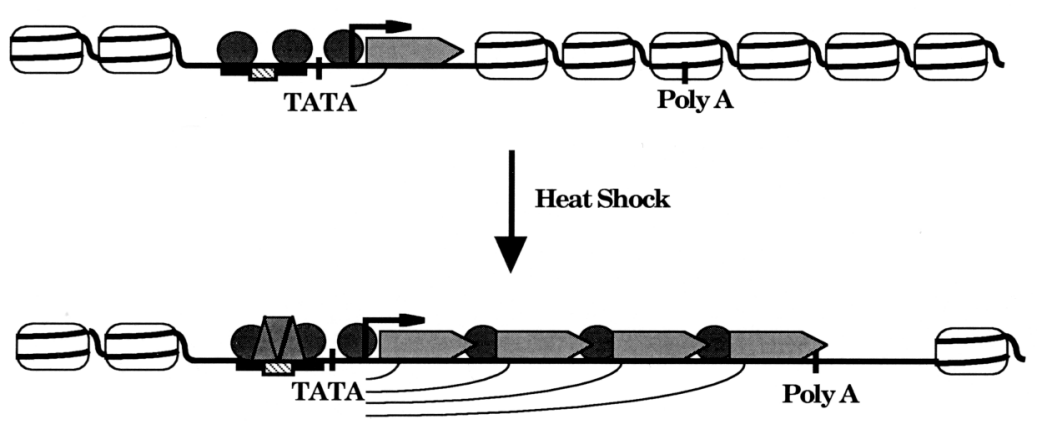

B

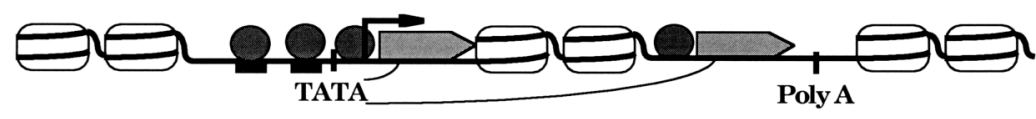

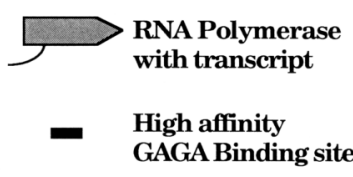

GAGA Factor

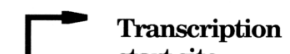

start site
Figure 8. Model depicting the distribution of GAGA protein on Drosophila genes. (A) Heat-inducible genes. In uninduced cells the heat shock genes contain an RNA polymerase that has initiated transcription but has paused after synthesizing a short transcript. The chromatin structure of the gene is shown as assembled into nucleosomes. However, the promoter/regulatory regions of these genes contain GAGA protein and are nucleosome free, and GAGA protein is shown as binding to both high- and low-affinity binding sites. After heat shock, HSF binds upstream and activates transcription. GAGA protein is now found distributed throughout the transcription units of the heat shock genes but not to more 3 ' nontranscribed regions. GAGA protein may be associated either directly or indirectly with the elongating polymerase complex. $(B)$ Constitutively expressed genes. In these cases, GAGA protein is also found to bind to the promoter/regulatory regions that contain high affinity binding sites, but, like the induced heat shock genes, is also distributed throughout the transcription unit.

\section{Distribution of GAGA protein on constitutively expressed genes}

The actin $5 C$ gene, whose promoter regions contain high affinity GAGA protein-binding sites that are essential for transcription (Chung and Keller 1990), also contains GAGA protein on both the $5^{\prime}$ and $3^{\prime}$ regions of the gene,

Table 1. Percent immunoprecipitation of the transcription units of various Drosophila genes by GAGA-specific antibody

\begin{tabular}{lc}
\hline Gene & $\begin{array}{l}\text { Percent } \\
\text { immunoprecipitation }\end{array}$ \\
\hline hsp70 & 0.015 \\
hsp26 & 0.09 \\
hsp23 & 0.03 \\
hsp83 & 0.01 \\
Actin 5C & 0.015 \\
Histone & 0.001 \\
rDNA & 0.002 \\
\hline
\end{tabular}

In cases where more than one fragment was used to examine the GAGA protein distribution (e.g., $h s p 70$ ), the number is the average of all the fragments. The numbers for the heat shock genes represent the level of GAGA protein on the induced gene. which is similar to what we have observed for the induced heat shock genes.

Not all actively transcribed genes contain a high level of GAGA protein. The his3/his4 divergent promoter region contains a CT-rich sequence that binds GAGA protein in vitro (Gilmour et al. 1989). Here, we find that GAGA protein can be cross-linked to a fragment containing these promoters in vivo, but at a lower level than is found for the induced heat shock genes. There are $\sim 100$ copies of the histone repeat in Drosophila (Lifton et al. 1977), and it is known that not all copies are equally active (Gilmour and Lis 1987). Also, the level of transcription of the histone DNA repeat is $\sim 1 / 40$ that of the fully induced $h s p 70$ gene (Gilmour and Lis 1985). If the level of GAGA protein is directly correlated with polymerase density, then the amount of histone repeat in GAGA protein immunoprecipitates would be $\sim 0.0004 \%$, whereas here we determine that a fragment containing this repeat is immunoprecipitated at a level of $0.001 \%$. However, the density of GAGA protein on a gene may also be dependent not only on polymerase density but on the quantity and quality of GAGA proteinbinding sites.

A fragment that spans the RNA polymerase I-tran- 
scribed rDNA locus was also immunoprecipitated by the GAGA protein-specific antibody, although at a low level (Table 1). GAGA protein may have no role in transcription of these genes. It was found previously that the Drosophila eve and $f t z$ proteins were distributed throughout nontarget genes at a level that was only $\sim 10$ fold lower than that found on genetically identified target genes (Walter et al. 1994). Consistent with this, homeo domain proteins have also been found to bind to lower affinity binding sites (Desplan et al. 1985; Beachy et al. 1988), as we have observed in vitro for GAGA protein. Therefore, the binding of GAGA protein to this region in vivo may result from the nonspecific binding to lower affinity sites that are randomly distributed throughout the genome. Also, as the rDNA repeat is transcribed at a high rate by RNA polymerase I (Miller 1981) and GAGA protein association is low, this result indicates that GAGA protein is not simply being recruited to actively transcribed genes.

\section{Conclusion}

GAGA protein has been suggested to function as an antirepressor, acting to disrupt the chromatin structure of a promoter. As predicted, GAGA protein is associated with the promoters of many Drosophila genes. Surprisingly, GAGA protein is also found distributed throughout the active transcription units of these genes. We propose that GAGA protein may initially be recruited to the promoter through high-affinity binding sites, and then binds to its lower affinity sites as it spreads through the transcription unit in concert with polymerase. As GAGA protein progresses through the gene it may function to open, or disrupt, the chromatin, allowing polymerase to elongate efficiently through the gene.

\section{Materials and methods}

\section{Generation of GAGA protein-specific antibody}

Polyclonal antiserum directed against GAGA protein was generated in rabbits against a GST-GAGA fusion protein overexpressed in Escherichia coli containing the pG2 $243-G A G A$ plasmid. The fusion protein consisted of the glutathione- $S$ transferase (GST) moiety fused in-frame to amino acids 244-519 of the GAGA protein. pG2 $2243-$ GAGA was subcloned from the pAR-GAGA expression vector (Soeller et al. 1993). Purification of the resulting antisera over an affinity column containing a Mal-GAGA fusion protein was done as described (Rio et al. 1986). The Mal-GAGA protein was overexpressed in E. coli containing the pM3-GAGA plasmid. pM3-GAGA was generated with primers to amplify by PCR the GAGA sequences contained in pAR-GAGA, and adding the 15 bases coding for the 5 amino-terminal residues absent in pAR-GAGA.

Antisera was purified further against specific regions of the GAGA protein by use of affinity columns containing GST-fusion proteins corresponding to specific subdomains of the GAGA protein. GAGA/Zn-specific antibodies were purified against a GST-GAGA fusion protein overexpressed in $E$. coli containing the pG2-244/363-GAGA plasmid. The fusion protein consisted of the GST moiety fused in-frame to amino acids 244-363 of the GAGA protein. The nature of the cloning rec- reates the zinc finger motif changing residues $361-368$ from HLELRHFA to HLEIHRDZ. GAGA/Q-specific antibodies were purified against a GST-GAGA fusion protein overexpressed in $E$. coli containing the pG $2 \Delta 435-G A G A$ plasmid. The fusion protein consisted of the GST moiety fused in-frame to amino acids $436-519$ of the GAGA protein. The GAGA/Zn and the GAGA/Q antibodies were then concentrated further by use of the Pharmacia Smart system. Each antibody was loaded onto a $100-\mu 1$ Mono Q column in $10 \mathrm{~mm}$ Tris- $\mathrm{Cl}(\mathrm{pH} 8.0), 10 \%$ glycerol, and eluted with $10 \mathrm{~mm}$ Tris- $\mathrm{Cl}(\mathrm{pH} 8.0), 10 \%$ glycerol, and $0.5 \mathrm{M} \mathrm{NaCl}$.

Purified GST-GAGA and Mal-GAGA proteins were examined on a $12 \%$ SDS-polyacrylamide gel. Drosophila Kc nuclei were prepared as described (Rougvie and Lis 1988). For Western analysis $2.5 \times 10^{5}$ nuclei were examined. Samples were transfered to nitrocellulose membranes, and detection was carried out by use of the ECL detection reagent kit (Amersham).

\section{In vivo $U V$ cross-linking}

Drosophila Kc cells were grown to a density of $\sim 1 \times 10^{7}$ cells/ $\mathrm{ml}$. Cells were heat-shocked in a jacketed spinner flask for 25 min at $37^{\circ} \mathrm{C}$. To inhibit RNA polymerase, elongation cells were treated with $125 \mu \mathrm{M}$ DRB 15,6-dichloro-1- $\beta$-D-ribofuranosylbenzimidazole) for $10 \mathrm{~min}$ prior to a $25-\mathrm{min}$ heat shock (Giardina and Lis 1993). Samples were irradiated with UV light from a long-wave UV light box for $10 \mathrm{~min}$ and then processed as described (Gilmour et al. 1991; Walter et al. 1994). The GAGA antibody was titrated to ensure immunoprecipitation of all GAGA protein-DNA complexes.

To give Kc cells an instantaneous heat shock, an equal volume of cells growing at $22^{\circ} \mathrm{C}$ was added to an equal volume of media prewarmed to $56^{\circ} \mathrm{C}$. When added together the temperature is instantly brought to the full heat shock temperature of $37^{\circ} \mathrm{C}$. The time of addition is taken to be zero. Samples of cells $\left(\sim 1.5 \times 10^{8}\right)$ were removed at each time point and given six flashes from a Xenon flashlamp (Xenon Corp.); the time point is the time of exposure to the first flash (see O'Brien and Lis 1993). Samples were then processed as described above. DNA labeling and Southern blot hybridizations were described previously (O'Brien and Lis 1993).

Quantitation was carried out either by autoradiography and densitometry (with a Bio-Rad model 620 video densitometer) or by direct detection with a Betagen Betascope 603 blot analyzer. In each case, a portion of the total amount of DNA present in the immunoprecipitation was also examined (Totals). It is therefore possible to quantitate the percent of immunoprecipitation of each fragment by comparing it with the total amount of DNA. Even though the percent immunoprecipitation of individual fragments by the GAGA antibody is low, it has been shown for RNA polymerase II and E. coli RNA polymerase that immunoprecipitation of transcribed fragments after UV crosslinking is proportional to the density of elongating polymerase (Gilmour and Lis 1984, 1987; O'Brien and Lis 1993). Therefore, the efficiency of immunoprecipitation of a DNA fragment by a specific antibody is proportional to the density of a specific protein on that fragment in vivo.

\section{In vitro footprinting}

Preparation of the end-labeled DNA for DNase I footprinting was performed by PCR amplification of a fragment from a plasmid containing the $h s p 70$ gene with primers described previously (Giardina et al. 1992). The top DNA strand was ${ }^{32} \mathrm{P}$-labeled by kinase treatment of the top strand primer before the amplification reaction (Giardina et al. 1992). Approximately 30 
fmoles of gel-purified, end-labeled DNA was incubated in a 30$\mu$ l binding reaction with pGST-GAGA protein in the following buffer: $80 \mathrm{mM} \mathrm{KCl} ; 10 \mathrm{~mm}$ HEPES at $\mathrm{pH} 7.9 ; 5 \mathrm{~mm} \mathrm{MgCl}_{2} ; 10 \%$ glycerol; $1 \mathrm{mM} \mathrm{DTT;} 0.1 \% \mathrm{NP}-40$. After a $30-\mathrm{min}$ incubation at room temperature, samples were treated with $1 \mu \mathrm{l}$ of a $20 \mu \mathrm{g} / \mathrm{ml}$ solution of DNase I for $1 \mathrm{~min}$. The reaction was stopped by adding $70 \mu \mathrm{l}$ of $50 \mathrm{~mm}$ EDTA, 1\% SDS; the DNA was ethanol precipitated, and run on a $5 \%$ polyacrylamide-urea sequencing gel (Giardina et al. 1992). The G-ladder was prepared by use of the standard dimethylsulfate reaction.

\section{In vitro immunoprecipitation of GAGA protein}

In vitro immunoprecipitations were done with full-length $\mathrm{Mal}-$ GAGA protein (see Fig. 1D) and fragments corresponding to the $5^{\prime}$ and $3^{\prime}$ portions of the $h s p 70$ gene. The plasmid p70X2.6 (Rougvie and Lis 1988), which contains the entire 2.4-kb transcription unit of the $h s p 70$ gene, was digested with $X h o I$ and BamHI to generate a $1.45-\mathrm{kb} h s p 705^{\prime}$ fragment, a $1.15-\mathrm{kb}$ hsp 70 3 ' fragment, and a $2.6-\mathrm{kb}$ vector band. DNA was labeled by Klenow reaction. Binding reactions were for $30 \mathrm{~min}$ on ice in GBB (GAGA binding buffer; $10 \%$ glycerol, 10 mM HEPES (pH $8.3\}, 200 \mathrm{mM} \mathrm{MgCl}_{2}, 1 \mathrm{~mm} \mathrm{DTT}, 80 \mathrm{mM} \mathrm{KCL}$, and $0.1 \%$ NP-40), at which point GAGA/Zn-specific antibody was added and incubated for an additional hour. Complexes were then precipitated with protein A-Sepharose beads (Sigma), preblocked with salmon sperm DNA.

\section{Acknowledgments}

This work was supported by National Institutes of Health grant GM 25232 to J.T.L.

The publication costs of this article were defrayed in part by payment of page charges. This article must therefore be hereby marked "advertisement" in accordance with 18 USC section 1734 solely to indicate this fact.

\section{References}

Bardwell, V.J. and R. Treisman. 1994. The POZ domain: A conserved protein-protein interaction motif. Genes \& Dev. 8: 1664-1677.

Beachy, P.A., M.A. Krasnow, E.R. Gavis, and D.S. Hogness. 1988. An Ultrabithorax protein binds sequences near its own and the Antennapedia Pl promoters. Cell 55:1069-1081.

Biggin, M.D. and R. Tjian. 1988. Transcription factors that activate the Ultrabithorax promoter in develomentally staged extracts. Cell 53:699-711.

Bond, B.J. and N. Davidson. 1986. The Drosophila melanogaster actin $5 \mathrm{C}$ gene uses two transcription initiation sites and three polyadenylation sites to express multiple mRNA species. Mol. Cell. Biol. 6: 2080-2088.

Cartwright, I.L. and S.C.R. Elgin. 1986. Nucleosomal instability and induction of new upstream protein-DNA associations accompany activation of four heat shock protein genes in Drosophila melanogaster. Mol. Cell. Biol. 6: 779-791.

Champlin, D.T., M. Frasch, H. Saumweber, and J.T. Lis. 1991. Characterization of a Drosophila protein associated with boundaries of transcriptionally active chromatin. Genes \& Dev. 5: 1611-1621.

Chung, Y.-T. and E.B. Keller. 1990. Regulatory elements mediating transcription from the Drosophila melanogaster Actin 5C proximal promoter. Mol. Cell. Biol. 10: 206-216.

Clos, J., T.W. Westwood, P.B. Becker, S. Wilson, K. Lambert, and C. Wu. 1990. Molecular cloning and expression of a hexam- eric Drosophila heat shock factor subject to negative regulation. Cell 63: 1085-1097.

Costlow, N.A. 1984. "Chromatin structure of Drosophila heat shock genes in Drosophila and yeast as probed with DNase I." Ph.D. thesis, Cornell University, Ithaca, New York.

Croston, G.E., L.A. Kerrigan, L.M. Lira, D.R. Marshak, and J.T. Kadonaga. 1991. Sequence-specific antirepression of Histone $\mathrm{Hl}$-mediated inhibition of basal RNA polymerase II transcription. Science 251: 643-649.

Dawid, I.B., P.K. Wellauer, and E.O. Long. 1978. Ribosomal DNA in Drosophila melanogaster. I. Isolation and characterization of cloned fragments. J. Mol. Biol. 126: 749-768.

Desplan, C., J. Theis, and P.H. O'Farrell. 1985. The Drosophila developmental gene, engrailed, encodes a sequence-specific DNA binding activity. Nature 318: 630-635.

Giardina, C. and J.T. Lis. 1993. Polymerase processivity and termination on Drosophila heat shock genes. I. Biol. Chem. 268: 23806-23811.

Giardina, C., M. Perez-Riba, and J.T. Lis. 1992. Promoter melting and TFIID complexes on Drosophila genes in vivo. Genes \& Dev. 6: 2190-2200.

Gilmour, D.S. and J.T. Lis. 1984. Detecting protein-DNA interactions in vivo: Distribution of RNA polymerase on specific bacterial genes. Proc. Natl. Acad. Sci. 81: 4275-4279.

_ - 1985. In vivo interactions of RNA polymerase II with genes of Drosophila melanogaster. Mol. Cell. Biol. 5: 20092018.

- 1986. RNA polymerase II interacts with the promoter region of the noninduced $h s p 70$ gene in Drosophila melanogaster cells. Mol. Cell. Biol. 6: 3984-3989.

- 1987. Protein-DNA cross-linking reveals dramatic variation in RNA polymerase II density on different histones repeats of Drosophila melanogaster. Mol. Cell. Biol. 7: 3341-3344.

Gilmour, D.S., G. Pflugfelder, J.C. Wang, and J.T. Lis. 1986. Topoisomerase I interacts with transcribed regions in Drosophila cells. Cell 44: 401-407.

Gilmour, D.S., G.H. Thomas, and S.C.R. Elgin. 1989. Drosophila nuclear proteins bind to regions of alternating $\mathrm{C}$ and $\mathrm{T}$ residues in gene promoters. Science 245: 1487-1490.

Gilmour, D.S., A.E. Rougvie, and J.T. Lis. 1991. Protein-DNA crosslinking as a means to determine the distribution of proteins on DNA in vivo. In Methods in cell biology (ed. B.A. Hamkalo and S.C.R. Elgin), vol. 35, pp. 369-381. Academic Press, Harcourt, Bruce Javanovitch, San Diego, CA.

Glaser, R.L., G.H. Thomas, E. Siegfried, S.C.R. Elgin, and J.T. Lis. 1990. Optimal heat-induced expression of the Drosophila hsp26 gene requires a promoter sequence containing (CT)n.|GA|n repeats. I. Mol. Biol. 211: 751-761.

Kellum, R. and P. Schedk. 1991. A position-effect assay for boundaries of higher order chromosomal domains. Cell 64: 941-950.

Lee, H.-S., K.W. Kraus, M.F. Wolfner, and J.T. Lis. 1992. DNA sequence requirements for generating paused polymerase at the start of hsp70. Genes \& Dev. 6: 284-295.

Lifton, R.P., M.L. Goldberg, R.W. Karp, and D.S. Hogness. 1977. The organization of the histone genes in Drosophila melanogaster: Functional and evolutionary implications. Cold Spring Harbor Symp. Quant. Biol. 42: 1047-1051.

Lu, Q., L.L. Wallrath, R.L. Allan, R.L. Glaser, J.T. Lis, and S.C.R. Elgin. 1992. Promoter sequence containing (CT) (GA)n repeats is critical for the formation of the DNase I hypersensitive sites in the Drosophila hsp26 gene. J. Mol. Biol. 226: 985-997.

Lu, Q., L.L. Wallrath, H. Granok, and S.C.R. Elgin. 1993. Distinct roles of $(\mathrm{CT}) \mathrm{n} \cdot(\mathrm{GA}) \mathrm{n}$ repeats and heat shock elements 
in chromatin structure and transcriptional activation of the Drosophila hsp26 gene. Mol. Cell. Biol. 13: 2801-2814.

Miller, O.L.J. 1981. The nucleolus, chromosomes, and visualisation of genetic activity. I. Cell. Biol. 91: 15s-27s.

Mirault, M.-E., M. Goldschmidt-Clermont, S. Artavanis-Tsakonas, and P. Schedl. 1979. Organization of the multiple genes for the 70,000-dalton heat-shock protein in Drosophila meIanogaster. Proc. NatI. Acad. Sci. 76: 5254-5258.

O'Brien, T. and J.T. Lis. 1991. RNA polymerase II pauses at the $5^{\prime}$ end of the transcriptionally induced Drosophila hsp 70 gene. Mol. Cell. Biol. 11: 5285-5290.

. 1993. Rapid changes in Drosophila transcription after an instantaneous heat shock. Mol. Cell. Biol. 13: 3456-3463.

O'Brien, T., S. Hardin, A. Greenleaf, and J.T. Lis. 1994. Phosphorylation of RNA polymerase II C-terminal domain and transcriptional elongation. Nature 370: 75-77.

O'Connor, D and J.T. Lis. 1981. Two closely linked transcription units within the 63B heat shock puff locus of $D$. melanogaster display strikingly different regulation. Nucleic Acids Res. 9: 5075-5092.

Rasmussen, E.B. and J.T. Lis. 1993, In vivo transcriptional pausing and cap formation on three Drosophila heat shock genes. Proc. Natl. Acad. Sci. 90: 7923-7927.

Rio, D.C., F.A. Laski, and G.M. Rubin. 1986. Identification and immunochemical analysis of biologically active Drosophila P element transposase. Cell 44: 21-32.

Rougvie, A.E. 1989. "Identification of a post-initiation rate-limiting step in the transcription of several Drosophila genes." PhD. thesis, Cornell University, Ithaca, New York.

Rougvie, A.E. and J.T. Lis. 1988. The RNA polymerase II molecule at the $5^{\prime}$ end of the uninduced $h s p 70$ gene of $D$. melanogaster is transcriptionally engaged. Cell 54: 795-804.

- 1990. Postinitiation transcriptional control in Drosophila melanogaster. Mol. Cell. Biol. 10: 6041-6045.

Soeller, W.C., S.J. Poole, and T. Kornberg. 1988. In vitro transcription of the Drosophila engrailed gene. Genes \& Dev. 2: 68-81.

Soeller, W.C., C.E. Oh, and T.H. Kornberg. 1993. Isolation of cDNAs encoding the Drosophila GAGA transcription factor. Mol. Cell. Biol. 13: 7961-7970.

Thomas, G.H. and S.C.R. Elgin. 1988. Protein/DNA architecture of the DNase I hypersensitive region of the Drosophila hsp26 promoter. EMBO /. 7: 2191-2202.

Thummel, C.S. 1989. The Drosophila E74 promoter contains essential sequences downstream from the start site of transcription. Genes \& Dev. 3: 782-792.

Tsukiyama, T., P.B. Becker, and C. Wu. 1994. ATP-dependent nucleosome disruption at at heat-shock promoter mediated by binding of GAGA transcription factor. Nature 367: 525532.

Udvardy, A., E. Maine, and P. Schedl. 1985. The 87A7 chromomere: Identification of novel chromatin structure flanking the heat shock locus that may define the boundaries of higher order domains. J. Mol. Biol. 185: 341-358.

Walter, J., C.D. Dever, and M.D. Biggin. 1994. Two homeo domain proteins bind with similar specificity to a wide range of DNA sites in Drosophila embryos. Genes \& Dev. 8: 16781692 .

Wiederrecht, G., D.J. Shuey, W.A. Kibbe, and C.S. Parker. 1987. The Saccharomyces and Drosophila heat shock transcription factors are identical in size and DNA binding properties. Cell 48: 507-515.

Wu, C. 1980. The $5^{\prime}$ ends of Drosophila heat shock genes in chromatin are hypersensitive to DNase I. Nature 286: 854860.

1984. Two protein-binding sites in chromatin impli- cated in the activation of heat shock genes. Nature 309: 229234.

Wu, C., S. Wilson, B. Walker, I. Dawid, T. Paisley, V. Zimarino, and H. Ueda. 1987. Purification and properties of Drosophila heat shock activator protein. Science 238: 1247-1253. 


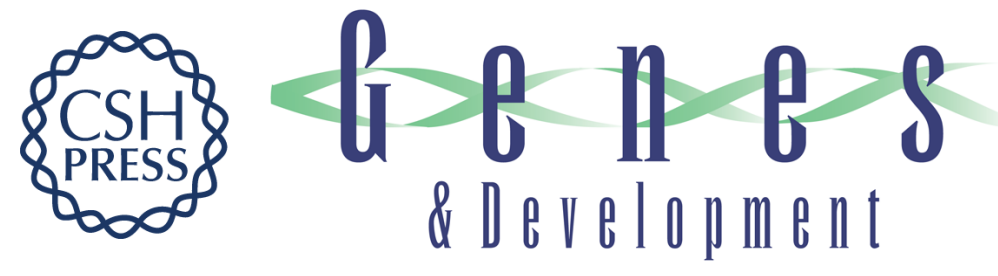

\section{Distribution of GAGA protein on Drosophila genes in vivo.}

T O'Brien, R C Wilkins, C Giardina, et al.

Genes Dev. 1995, 9:

Access the most recent version at doi:10.1101/gad.9.9.1098 $\begin{array}{ll}\text { References } & \begin{array}{l}\text { This article cites } 46 \text { articles, } 25 \text { of which can be accessed free at: } \\ \text { http://genesdev.cshlp.org/content/9/9/1098.full.html\#ref-list-1 }\end{array}\end{array}$

License

Email Alerting

Receive free email alerts when new articles cite this article - sign up in the box at the top Service right corner of the article or click here.

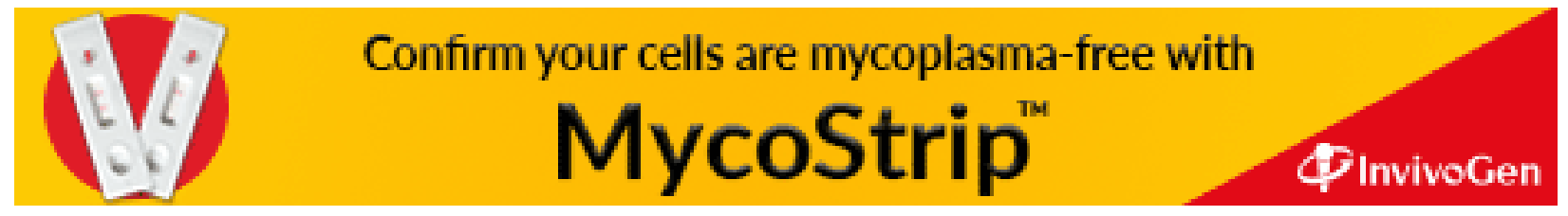

